\title{
Water consumption analysis using IoT
}

\author{
Dr.A.Thomas Paul Roy ${ }^{1}$, Dr.S.Satheesbabu²and Dr.S.K.Somasundaram ${ }^{3}$ \\ ${ }^{1}$ Professor, Department of CSE., PSNA College of Engineering and Technology, Dindigul \\ ${ }^{2}$ Associate Professor, Department of CSE., PSNA College of Engineering and Technology, Dindigul \\ ${ }^{3}$ Assistant Professor(Selection grade), Department of IT., PSG College of Technology, Coimbatore
}

\begin{abstract}
Water is a fundamental asset for people, and its administration is a central point of contention. To conserve water, this system improves the expanded use of water. Internet of things is arrangement of interrelated processing gadgets, computing entities, vehicles, home machines and different things installed with electronic chips and sensors. The system is planned utilizing Nodemcu, ESP8266 and sensors. ESP8266, which is a less cost cloud microchip. This framework will comprise of a water pipe with water flow meter associated with it and a Nodemcu board and ESP8266 associated with it. First we utilize a water flow meter and gather the information as water moves through it.ESP8266 Wi-Fi module is a minimal effort CPU that gathers and sends the data to the cloud. We utilize the Nodemcu to arrange between water flow meter and the ESP 8266 module and afterward utilize the Thing speak Internet of things investigation stage to break down and show the information in visual organization. The yield of this system will be utilized for checking the water and it tends to be shown visually through the graph. The venture can be fundamentally valuable for household and agricultural purposes as it assists with limiting the loss of water..

Index Terms: Internet of Things (IoT), Embedded systems, Wi-Fi module, water flow Sensors.
\end{abstract}

Article Received: 20 September 2020, Revised: 30 November 2020, Accepted: 18 December 2020

\section{INTRODUCTION}

The drinking water has gotten exorbitant and the ground water level is decreased day by day. The new water utilization is expanded to an enormous degree in the course of recent years. All the people are confronting inconvenience because of the increased utilization of water. The IoT based sensor venture which is an organization of physical computing devices, gadgets that are implanted with hardware, sensors, and availability that empowers these gadgets to interface and trade information, making open doors for more straightforward unification of the physical world into Cybernetics framework. This system utilizes the web of things for checking the water. Nodemcu, ESP8266 are the principle parts that we use in this system. ESP8266 is an ease microcontroller that permits Nodemcu to associate with a Wi-Fi network. The water coursing through a line can be estimated and checked using IoT and the concerned results are shown visually.

\section{LITERATURE SURVEY}

Managerial task of Water utilization in respect to household and agriculture purpose will be the risky task. To utilize the water productively, a system to monitor the water flow must be made. The primary point is to enable the individuals to know the measure of water that is adequate and forestall the wastage of water. It is non-renewable, so once in the event that it gets depleted it can't be recharged .The investigation examines the plan and advancement of the framework having minimal effort to control the checking of water The goal is of ease regulator which incorporates arrangement of coordinated tangible which licenses inward perception for nature of water Using the web, we can move the important cloud worker and the information will be gotten by a client terminal which are being claimed by clients. The water weight final product is shown on distributed storage. The
Thing talk is a portion of ready frameworks is coordinated moreover. This sort of plan can give an early ready for framework for the versatile water quality. The Thing Speak IOT analytic can be utilized as a section to show the qualities obviously .The equipment, for example, Nodemcu and ESP8266 are needed to check or control the progression of water through a pipeline. The framework is likewise practical as we utilize the minimal effort central processor ESP8266 and Nodemcu .These are the references from where the substance has been perused.

In 2015, Thinagaran perumal, Md Nasir Sulaiman, Leong presented "Internet of things Enabled water System". They had designed and implemented "Water monitor system by using Internet of things" for the real time scenario. This system was a low cost framework, which involves a integrated sensory system and permits inner observation of the quality of the water Through web the significant wearing information are moved to the cloud workers and this information is gotten by client serious which is possessed by the customers. The estimation aftereffect of the water is appeared in the cloud server . The Thing speak is a segment of the alert system and it is integrated also. This sort of goal can have the option to use decently and successfully by private client or by the mechanical client and a lot more water utilities. By utilizing Internet of Things, this kind of goal can give early and quick ready framework for the convenient water quality.[7]

In 2013 Saima Maqbool, Nidhi Chandra presented a system entitled on ''Real time Monitoring and control of water system wirelessly using Zigbee 802.15.4"in which the design includes various components playing out a specific capacity of occupations detects the information and the information is moved to the end apparatus or machine inverter. The needy information is detected and composed 
by the network router. The Router will have the option to accumulate the information from the end device like XBee which thusly structure sensor and sends this information to the coordinator. Using computer system, all the information are showed and presented. From the PC a specific assignment can be executed, for example, "SMS" can be sent to client's framework and at caution can be blows at the craving medium. All the information can be put away and kept in the data set, Which can likewise be used to actualize "water expertsystem" through a drawn out examination.

In 2017, Divya C, Nikhil Gowda, Suhas Shastry, Yashwanth J,Achyutha Preksha presented "IoT based water supply monitoring". It is discovered that 22 out of 32 urban communities in the nation are confronting lack of water gracefully consistently. This emergency may be a direct result of both characteristic and human elements, i.e either on account of water being squandered by people in a few different ways every day or may be because of diminishing precipitation. This framework planned by N. Vijay kumara a minimal effort systemfor checking their nature of water utilizing IOT is proposed. Boundaries to decide the nature of water, for example, $\mathrm{pH}$, conductivity, etc are checked. This has been completed with the assistance of sensors. Raspberry pi is utilized as regulator. Issue here is that solitary the nature of water is observed yet not its stream control.

Thinagaran Perumal have proposed IoT based water monitoring frameworkthat checks water level progressively. Water level sensor is utilized to check the level.

ATmeg328p is utilized as a regulator. After the water level arrives at the ideal boundary, a signal is sent to social network like Twitter. But the main issue here is that only the water level is checked however not the quality and nature of water. In this work 5 people have been cooperated to finish the entire work. Yet, some of them have dealt with the other venture works, however some of them took a shot at the premise of IOT.[9-13] So this has been taken as the reference of my system.[6]

In 2018 Sugapriya, Ramya, Ramyadevi, Rakshaya, Rashmi presented "SMART WATER QUALITYMONITORING SYSTEM". In 2013, Nivit Yadav had proposed "CPCB Real Time Quality water Monitoring Maintenance" framework. In this framework, the quality of water in Ganges and Yamuna river is tested by using sensor.

In 2011, Satish Turken, Amruta Kulkarni, "Solar Powered Quality water Monitoring System using Wireless Sensor Network" is designed.This base station has assembled the data at inaccessible far off territory sensors. The Base Station is related with ZigBee module which is fueled by daylight baseboard [2]. In 2016, M N Barabde, the System is utilized for deciding the physiochemical elements of the nature of water, for example, movement, conductivity, temperature, $\mathrm{PH}$ and oxidation bringing down potential utilizing ZigBee.[3]

\section{III.EXISTING SYSTEMS}

There are a great deal of existing models of savvy water observing framework that are available in the market. The greater part of these frameworks primarily center around controlling little regions through the web. These framework utilize various sorts of remote correspondence strategies, for example, Wi-Fi, Bluetooth. Every one of these frameworks have their own extraordinary points of interest and weaknesses.

\section{IV.SYSTEM ARCHITECTURE $\mathrm{V}$.}

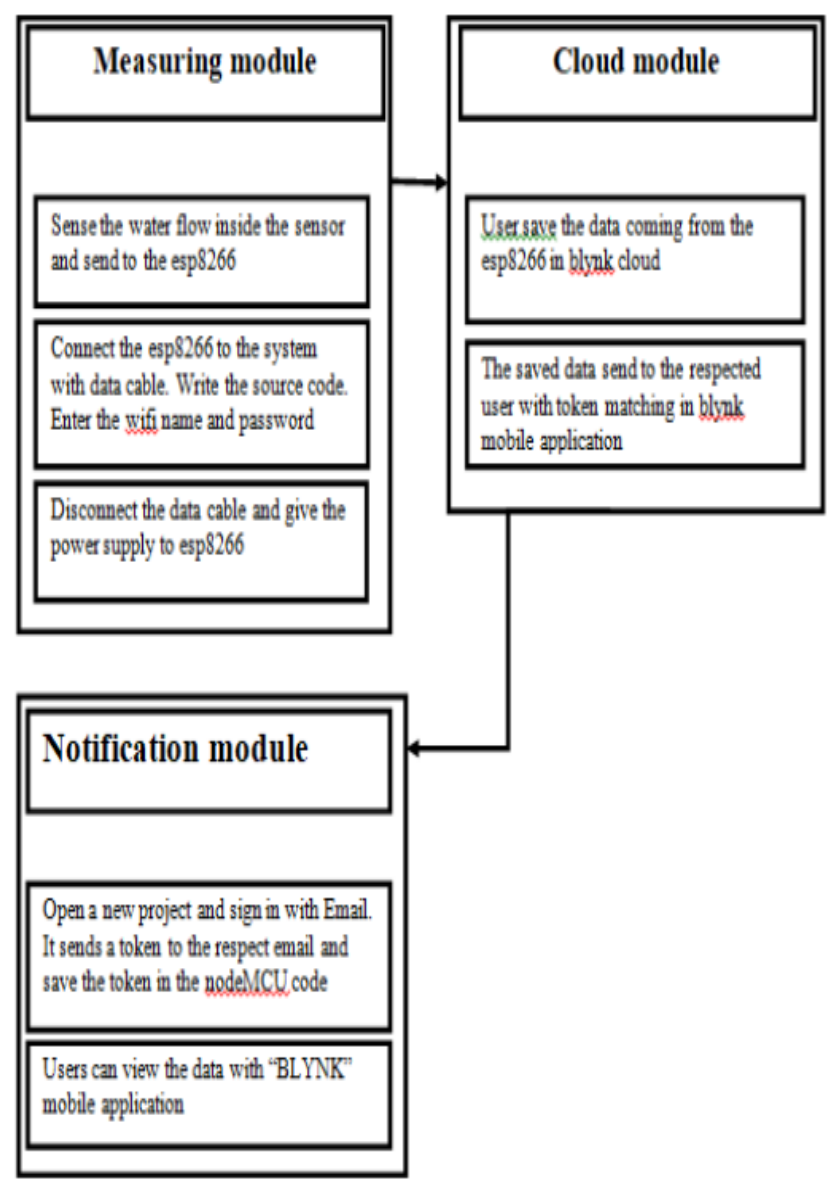

System Framework

This above figure portrays about association among modules and the Nodemcu board where the information is gotten and sent to the Thing talk investigation. The framework is associated with the web through ESP8266 wifi module shows the graphical portrayal on the screen.

\section{PROPOSED SYSTEM}

Here the fundamental issue is the water flow monitoring isn't useful for all the assets so therefore and to get helpful for all the assets the system has been presented. A significant number of the individuals gets accommodating and the water gets helpful as well. The proposed system 
utilizes esp8266 wifi module, ncu mode, sensors like water stream sensor.

\section{FEATURE AND ADVANTA GES OF THE PROPOSED SYSTEM \\ 1. Creating awareness about consumption and wasting of water \\ 2. We can see our consumed amount of water from everywhere with mobile \\ 3. Easy to find the leakage of water.}

\section{METHODOLOGY}

1. Inclusion of water flow sensor

2. Nodemcu and its operation

$3 . \quad$ Notification module

Module 1: Inclusionof water flow sensor

Principle: The water stream meter is a sensor which is utilized to detect the pace of stream of water through the pipe line and shows the measure of water which has been gone through the pipe line. The water flow sensor is fixed inside the pipe line to finds the flow stream and measure of water went through the line. This sensor comprises of a plastic body and an engine to make the water flow stream effectively through the line.

This sensor consists of a plastic body and a motor to make the water flow easily through the pipe line. Water flow sensor comprises of a plastic valve from which water can pass.

A water rotor alongside a Hall Effect sensor is available the sense and measure the water stream. At the point when water moves through the valve it turns the rotor. By this, the change can be seen in the speed of the engine. This change is determined as yield as a heartbeat signal by the Hall Effect sensor. Hence, the pace of stream of water can be estimated.

The primary working guideline behind the working of this sensor is the Hall Effect. As per this guideline, in this sensor, a voltage distinction is incited in the conductor because of the revolution of the rotor. This actuated voltage contrast is cross over to the electric flow. The water stream sensor can be utilized with hot waters, cold waters, warm waters, clean water, and grimy water too. These sensors are accessible in various measurements, with various stream rate ranges.

These sensors can be effectively interfaced with microcontrollers like Arduino. For this, an Arduino microcontroller board for handling, a Hall Effect water stream sensor, a $16 \times 2$ LCD show, and Breadboard interfacing wires are required.

The sensor is set at the water source channel or at the launch of the pipe.The sensor contains three wires. Red wire to associate with flexibly voltage. Dark wire to associate with ground and a yellow wire to gather yield from Hall impact sensor. For flexibly voltage $5 \mathrm{~V}$ to $18 \mathrm{~V}$ of $\mathrm{DC}$ is required.

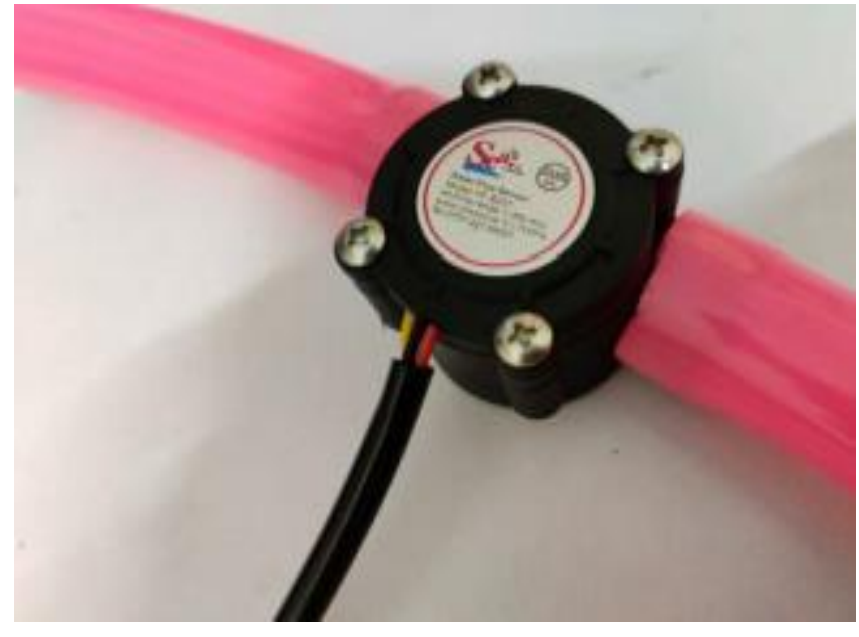

Water flow sensor

Module 2: NODEMCU AND ITS OPERATION

Principle: The node mcu sensor is integrated with wifi. The sensor receive the data coming inside the board and send the data to the blynk cloud respect to the token generated with particular email id. The data is in the raw text format. The raw formatted data can be converted to the json data. can get the necessary information with the individual pin information and can be shown in versatile blynk application. NodeMCU is an open source IoT platform.It incorporates firmware which runs on the ESP8266 Wi-Fi SoC from Espressif Systems, and hardware equipment, which depends on the ESP-12 module. The term "NodeMCU" by default refers to the firmware rather than the dev kits. The firmware makes use of the Lua scripting language. It depends on the eLua system and based on the Espressif Non-OS SDK for ESP8266. It utilizes many open source ventures, for example, Lua-cjson and spiffs. LUA based interactive firmware for Expressif ESP8622 Wi-Fi SoC, as well as an open source hardware board that contrary to the \$3 ESP8266 Wi-Fi modules includes a CP2102 TTL to USB chip for programming and debugging, is breadboard-friendly, and can simply be powered via its micro USB port. In the wake of setting up ESP8266 with Node-MCU firmware, we should see the IDE (Integrated Development Environment) required for improvement of NodeMCU.

\section{NodeMCU with ESPlorer IDE}

Lua scripts are commonly used to code the NodeMCU. Lua is an open source, lightweight, embeddable scripting language based on head of $\mathrm{C}$ programming language. For more information about how to write Lua script for NodeMCU refer Getting started with NodeMCU using ESPlorerIDE

\section{NodeMCU with Arduino IDE}

Here is another method of creating NodeMCU with a notable IDE for example Arduino IDE. We can likewise create applications on NodeMCU utilizing Arduino advancement condition. This makes simple for Arduino designers than learning new dialect and IDE for NodeMCU. For more data about how to compose Arduino sketch for 
NodeMCU allude Getting started with NodeMCU utilizing ArduinoIDE.

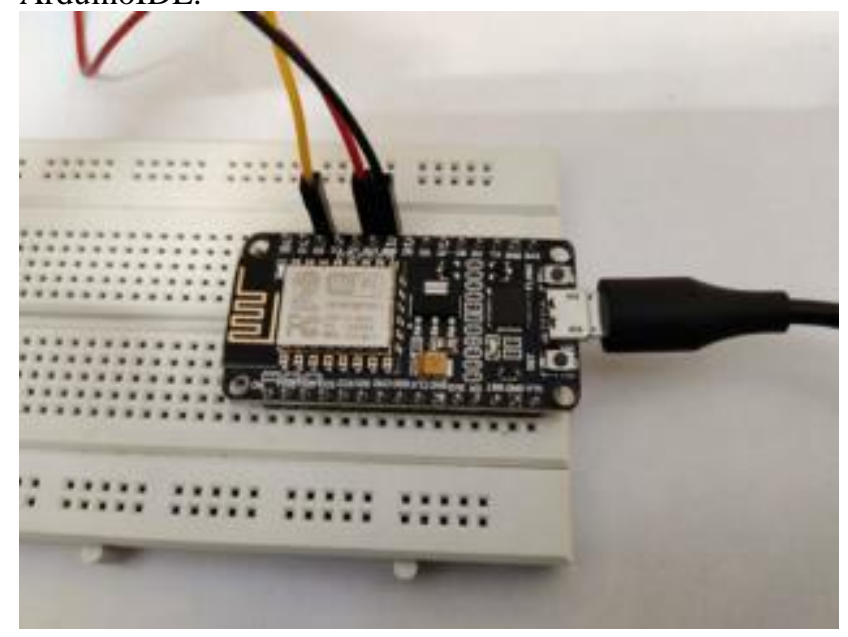

Nodemcu module

\section{Module3: NOTIFICATION MODULE}

Principle: The spared information send to the regarded client with token coordinating inblynk mobile application. To manage this module, Open another task and sign in with Email. It sends a token to the respective email and spare the token in the nodeMCU code. Users can see the information with "BLYNK" versatile application. A home automation system is an automating themajority of electronic and electrical undertakings inside a home. It utilizes a mix of equipment and programming to empower control and the executives over apparatuses and gadgets inside a home. Home automation not only refers to reduce human efforts but also energy efficiency and time saving. Here our system will facilitate home automation by using ESP8266 - WiFi SoC and Blynk Playstore App.

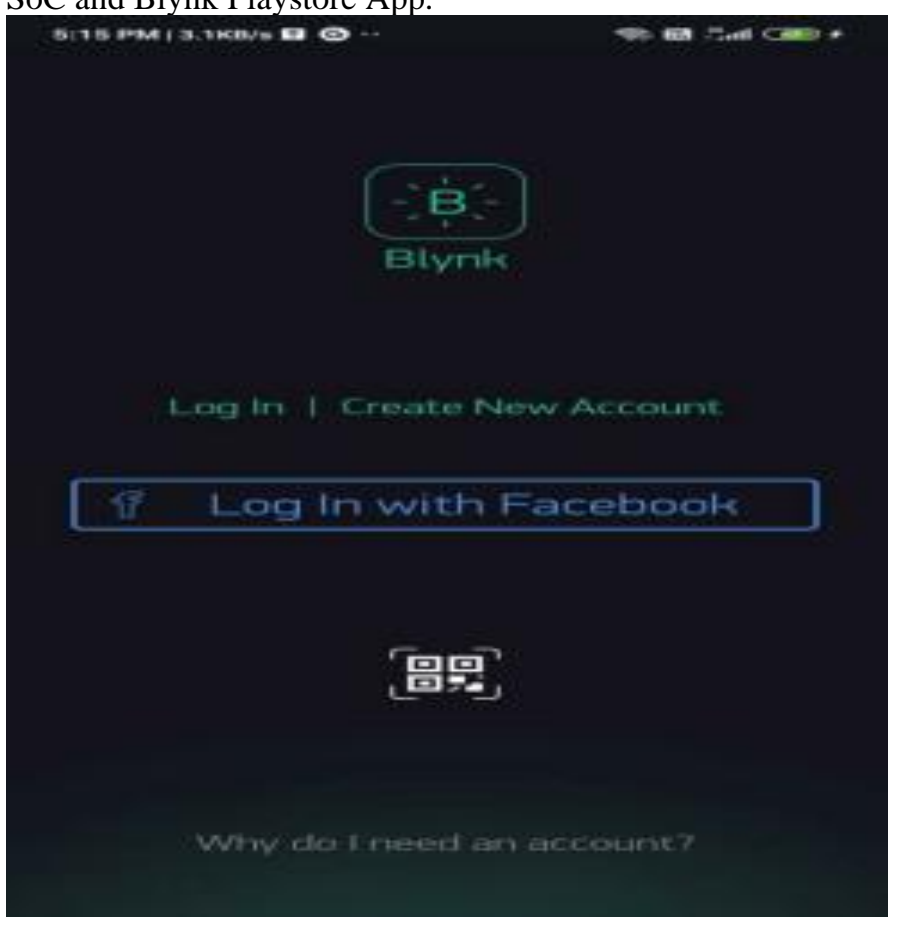

Notification module
VII. CONCLUSION

Our goal of this research work was to establish an adoptable, flexible, economical, easily configurable and most importantly, a portable system which can tackle our water wastage issue. It is a robust and powerful system and small in size. Our proposed system for water consumption analysis comes under the field of Internet of Things (IoT). Our fundamental goal was to plan a keen framework for making the attention to devouring and squandering of water and forestall the spillage of. This analyzing feature can also help us in finding whether there is any leakage in the tank or not. Nowadays liquid consuming and monitoring is a vital task in many industries too like oil, automotive etc. Using our smart system any end user can analyze the usage and also detect the leakage in the tanks of these industries.

\section{REFERENCES}

[1] Nivit Yadav, "CPCB Real Time Water Quality Monitoring", Report: Centre for Science and Environment, 2013.

[2] M N Barabde, S R Danve Continuous water quality monitoring system for Water resources at remote places, 2015.

[3] Pavana N R, Dr.M.C. Padma, "Design of Low Cost System for Real Time Monitoring of Water Quality Parameters in IOT Environment",2016.

[4] MS T DEEPIGA AND MS A SIVASANKARI,"Smart Water Monitoring system using wireless sensor network,2015.

[5] Divya c, Nikhil Gowda, Suhas Shastry, Yashwanth J,Achyutha Preksha A "IOT BASED WATER SUPPLY MONITORING".

[6] Quio tie-zhn, online quality monitoring system based on GPRS/GSM,2010.

[7] Thinagaran perumall,Md nasir sulaiman,leong,"internet of things embeded water system".2015

[8] SatishTurken,AmrutaKulkarni,"Solar Powered Water Quality Monitoring System using Wireless Sensor Network", IEEE Conf. on Automation, Computing, communication, control, and compressed sensing.

[9] Prabu, A. V., \& Sateesh, G. (2019). Kumar Performance Analysis and Lifetime estimation of Wireless Technologies for WSN (Wireless Sensor Networks)/IoT (Internet of Things). Application Jour of Adv Research in Dynamical and Control Systems, 11(1), 250-258.

[10] Manikandan, R and Dr.R.Latha (2017). "A literature survey of existing map matching algorithm for navigation technology. International journal of engineering sciences \& research technology", 6(9), 326-331.Retrieved September 15, 2017.

[11] Prabu, A. V., \& Kumar, G. S. (2019). Hybrid MAC based adaptive preamble technique to 
improve the lifetime in wireless sensor networks. J. Adv. Research in Dynamical \& Control Systems, 11(1), 240-249.

[12] R. Sathish, R. Manikandan, S. Silvia Priscila, B. V. Sara and R. Mahaveerakannan, "A Report on the Impact of Information Technology and Social Media on Covid-19," 2020 3rd International Conference on Intelligent Sustainable Systems (ICISS), Thoothukudi, India, 2020, pp. 224-230, doi: 10.1109/ICISS49785.2020.9316046.

[13] K Vijaya Manasa , A V Prabu , M Sai Prathyusha , S Varakumari (2018) .Performance monitoring of UPS battery using IoT" International Journal of Engineering \& Technology, 7 (2.7).352-355.

[14] Prabu, A. V., Tolada, A., Mishra, J., Rajasoundaran, S., \& Deepak, T. Automatic vehicle parking space booking system using IoT. Materials Today: Proceedings.

[15] Prabu, A. V., Chandra, Y. S., Kumar, G. S., \& Zeenath, S. Residential energy management system using IoT. Materials Today: Proceedings. 